\title{
A PERSPECTIVA DO ARQUÉTIPO FEMININO NA ENFERMAGEM
}

\author{
THE PERSPECTIVES OF FEMININE ARCHETYPE IN NURSING \\ LA PERSPECTIVA DEL ARQUETIPO FEMENINO EN ENFERMERÍA
}

\author{
Valéria da Silva Fonseca' \\ Lúcia Helena Garcia Penna²
}

\begin{abstract}
RESUMO: O presente trabalho propōe um novo enfoque sobre a origem feminina da Enfermagem, a partir da ótica arquetipica, e de suas características tão pouco mutáveis no decorrer da história. Acreditamos que as mesmas sejam resultantes de um inconsciente coletivo, ou seja, um modelo primitivo, idéias inativas. As perspectivas adotadas do arquétipo feminino estão relacionadas com a base histórica e social da Enfermagem e com a pressuposta atividade-fim de cuidar, onde estaria suas (in)visiveis influências na Enfermagem. Durante anos e à luz de nossa vivência profissional, identificamos que a atividade-essência da profissăo - O CUIDAR, têm o sentido básico do gênero feminino - PROTEGER, PROMOVER, PRESERVAR o se humano, características estas que transcendem o mundo físico e material. Através dessas reflexōes, sugerimos a possibilidade de que as (os) enfermeiras(os) possuem uma consciência individual, que não corresponde a uma tabula rasa, mas que sofre influência de predisposiçōes herdadas que constitui-se no inconsciente coletivo.
\end{abstract}

PALAVRAS-CHAVE: arquétipo feminino, Enfermagem, cuidar

\section{INTRODUÇÃO}

"O que se precisa é de algum tipo de evidência empírica, de alguns dados de observação que, ao confrontarem teoria com fato, transformem uma hipótese coerente em hipótese plausivel".

J.J. CLARKE

Basicamente, a Enfermagem possui no CUIDAR/CUIDADO sua própria essência, a qual tem sido atribuída, histórico-culturalmente, ao gênero feminino.

Como apreciadoras do assunto e, no sentido de procurar entender esses determinantes e responder questionamentos fundamentais, como " Quem sou?", "De onde venho?", Por que eu?", os quais constituem inquietações importantes que circundam nossa vivência diária, tentaremos estudar a Enfermagem, sob a ótica arquetipica de sua origem feminina e de suas características tão pouco mutáveis, no decorrer da história.

O presente trabalho consiste, "a priori", em um estudo bibliográfico e reflexivo sobre as seguintes temáticas: Teoria do Arquétipo, Inconsciente Coletivo e o Cuidar- essência da Enfermagem.

A partir da hipótese da Teoria Arquetipica, resultante desse inconsciente coletivo, ou

1 Enfermeira Obstetra do Instituto Fernandes Figueira/FIOCRUZ, Enfermeira Obstetra do Instituto Municipal da Mulher Fernando de Magalhăes/RJ, Mestranda do Curso de Mestrado em Enfermagem da UNI-RIO

${ }^{2}$ Enfermeira Obstetra, Professora Auxiliar do Departamento de Enfermagem Materno-Infantil da FEUERJ. Mestranda do Curso de Mestrado em Enfermagem da UNI-RIO. 
seja, modelo primitivo, idéias inatas, cuja idade é impossivel determinar com precisão acreditamos que a Enfermagem tenha, em sua origem, tais influências.

O interesse em realizar este trabalho, desenvolveu-se a partir das Disciplinas de Filosofia e de Gênero, Sexualidade e Saúde, do Curso de Mestrado em Enfermagem da Universidade do Rio de Janeiro, onde surgiram discussões e reflexões sobre a origem, suas características, atividades e representações sociais, basicamente femininas.

Considerando ser este trabalho a primeira aproximação das autoras com o tema em questão e, não sendo o mesmo, de nossa área de domínio por constituir-se de conteúdos de especificidade inerentes à Filosofia e Psicologia tem ele, inicialmente, um caráter mais reflexivo, a partir de levantamento teórico sobre a temática dos Arquétipos, atendendo ao aspecto feminino e, sua possivel influência na Enfermagem.

Adotaremos, para fins deste estudo, perspectivas referentes a arquétipo como base histórica e social da Enfermagem, correlacionando com a pressuposta atividade fim de CUIDAR e onde estariam suas (in)visíveis influências na Enfermagem.

\section{BUSCANDO CONHECER UM POUCO DO INCONSCIENTE COLETIVO}

A idéia filosófica do inconsciente, pertence ao século passado e foi perdendo seu espaço, em função do materialismo e positivismo emergentes à época.

Posteriormente, adota outras formas retornando dentro de uma psicologia médica de orientação cientifico-natural, designado, por Freud, como o lugar de reunião dos conteúdos esquecidos e reprimidos e, portanto, com enfoque de natureza estritamente pessoal, ainda que o mesmo já verificasse a presença de caracteres arcaicos mitológicos do inconsciente.

Jung, (1970) no entanto estratifica esse inconsciente em duas formas: o inconsciente pessoal, originado na experiência pessoal e aquisição individual; este descansa sobre outra camada mais profunda, de caráter inato, portanto desvinculado da experiência individual, daí a assimilação do termo "coletivo", que lança-nos a perspectiva do "universal",

Sua tese foi tida como um escândalo, especialmente num momento em que a psicologia médica, convivia com os pressupostos freudianos do inconsciente individual, sendo objeto de escárnio, descrença e como bem nos lembra Clarke (1992), tida como "misticamente concebida" por Wilhem Reich. Já os psicólogos modernos, consideram e crêem que o comportamento caracteristicamente humano, advém de um processo de aprendizagem, contrapondo-se aos etologistas para os quais as qualidades humanas correspondem a uma construção cultural $\mathrm{e}$ não transmissão genética. À margem das pressuposições de Clarke (1992), demonstrou que acima de todas essas indagações, o pensamento junguiano traduz-se em hipótese plausível de reconhecida contribuição aos estudos do comportamento e evolução humana.

Julgamos elucidatório apresentar alguns pensamentos e idéias atribuídas ao inconsciente coletivo por Jung (1970): "(...) matriz de todas as ocorrências psiquícas", "(...) fundamento anímico de natureza suprapessoal em todos os homens", "(...) é um modelo hipotético e irrepresentável", "(...) sua hipótese não é mais ousada do que se supor que há instintos".

Não tencionamos proporcionar um estudo de profundidade sobre o inconsciente coletivo, o que decerto demandaria tempo e domínio específico da área, contudo é de nosso interesse oferecer uma breve noção, do que Jung, denominou o INCONSCIENTE COLETIVO.

A expressão, segundo Clarke (1992), pode induzir a um erro, na medida em que presssupõe algum tipo de psique supra-pessoal, o que colaborou para o perfil de mistico atribuído a Jung mas, na realidade, o que pretendia afirmar era que o inconsciente coletivo era como um potencial para certos tipos de atividade psíquica tipicamente humanas, não um fato mas, sim, uma disposição para.

Ao potencial, bem como aos conteúdos desse inconsciente coletivo, Jung denominou ARQUÉTIPOS. 


\section{ARQUÉTIPO - ESSÊNCIA FEMININA}

O significado de arkhé, em Homero, refere-se ao que está no começo, no princípio, na origem de alguma ação, de algum discurso. É o ponto de partida, e, daí, deriva-se a palavra arquétipo como tipo ou modelo primitivo de uma coisa. Dentre as caracteristicas dos primeiros filósofos, está a busca da arkhé, personificando a "busca do principio absoluto, ao que vem e está antes de tudo, no começo e no fim de tudo, o fundamento, o fundo imortal e imutável, incorruptível de todas as coisas, que os faz surgir e as governa", segundo Chauí (1994).

A expressão "arquétipo" foi, inicialmente, utilizada pelo filósofo judeu Filon de Alexandria (nascido no ano 10 a.C.), resultando de uma retomada da idéia platônica, que defendia a aquisição do conhecimento como o reencontro, a recordação de Formas ou Idéias pré-existentes aprendidas antes mesmo do nascimento. Tais Formas ou Idéias, tornariam-se evidentes e trazidas à superficie por intermédio de um estimulo de experiência sensorial. Influencia, posteriormente o pensamento cristão, através dos escritos teológicos de Santo Agostinho (séc. III d.C.), onde ele sustenta que a imagem de Deus está gravada em cada alma. Perpassa a filosofia escolástica medieval onde, a idéia de arquétipos é assemelhada a imagens naturais, gravadas na mente humana, chegando, por fim, a Jung que crê existir uma paridade entre o conceito hindu de carma e sua própria teoria de arquétipos.

Entretanto, é na filosofia de Kant, que Jung reflete e encontra um "feedback", crendo inclusive, segundo Clarke (1992), que seu próprio conceito de arquétipo, era uma "derivação e uma ampliação das idéias do pensador alemäo". Assim, como Kant acreditava que os arquétipos não deveriam ser compreendidos em termos metafísicos, mas, sim fenomenais, enfatizando a necessária estrutura da experiência e desvinculando da essência das coisas. Adota a atemporalidade proposta por Kant, em que não se pode delimitar espaço e tempo em si, a não ser a partir da experiência que destes venhamos a desenvolver.

Nesta concepção em que renova-se a noção do arquétipo como elemento atemporal, já que defendido dentro de um processo dinâmico, em que mesclam-se a origem, o aqui e agora torna-se impossivel delimitar passado e presente. Este aspecto, remete-nos à transformação da teoria do conhecimento em metafísica quando, Chaui (1995) diz que Kant afirma o sujeito como uma estrutura universal, idêntica para todos os seres humanos, em todos os tempos e lugares.

A elaboração conceitual arquetipica de Jung, foi além dos pressupostos kantianos, e situou o arquétipo como uma possibilidade de evolução no decorrer dos períodos históricos humanos como resposta à experiência concreta e que, como tal, abrangia toda faixa possivel de experiência humana, afetiva e avaliativa.

Retomando a afirmação kantiana da estruturação universal do sujeito e reinterando a citação de Jung (1970) de que: "inconsciente coletivo significa que a consciência individual é tudo, menos uma tábula rasa, mas é influenciado no mais alto grau por predisposiçōes herdadas. Abrange em si a vida psiquica de nossos ancestrais, retroagindo até os primórdios mais remotos". Então pergunta-se: como se dá este processo? Através de que mecanismo, são herdadas tais predisposiçöes?

Alguns autores, citados por Clarke (1992) como Stevens e Samuels tentaram discutir essa questão ora à luz do lamarckismo, ora à luz do darwinismo, no entanto, o próprio Jung (1964) esclarece e responde aos seus críticos: "o termo arquétipo é muitas vezes mal compreendido, julgando-se que expressa certas imagens ou motivos mitológicos definidos. Mas estes nada mais são que representaçōes conscientes. Seria absurdo supor que representações tăo variadas pudessem ser transmitidas hereditariamente...Meus críticos supuseram erradamente, que eu desejava referir-me a representações herdadas e, em conseqüência, rejeitaram a idéia do arquétipo como se fosse apenas uma superstição" 
Crê Jung (1964) que o arquétipo corresponde à tendência de formar representações de um motivo, de tal monta que podem tomar inúmeras variações de detalhes, dos quais encontraremos exemplos claros, à luz da abordagem arquétipica, quando através da lente histórica, observamos os cultos cretenses, ainda que pouco saibamos, centravam-se no feminino, representado pela figura da Grande Mãe que é transposta em deusas como Hera, llítia, Perséfone, Britomártis todas, invariavelmente, tidas como algo acima e além: mãe dos deuses, mãe dos homens e de tudo quanto existe na terra. Assimiladas "a posteriori" pelos gregos, ainda que com funçōes diferentes, permaneceram com o traço comum, e peculiar da FECUNDIDADE.

Esta linha de pensamento encontramos em vasta literatura (Clarke (1992), Duby; Perrot (1990), Jung (1970), Neumann (1955)) a referência à Grande Mãe, advinda da história da religião e que engloba as mais distintas configurações do tipo de uma deusa-mãe.

A elaboração dessa crença buscou subsídios em sítios arqueológicos que correspondiam ao período Neolitico II ( 3000-2600), na Grécia. Dessa forma, a evidência de uma acrópole, de uma cidade fortificada, contendo em seu reduto central um mégaron (grande sala) é indicativo, segundo Brandão (1988), de uma organização monárquica e, assim sendo, uma civilização agrícola, no qual e encarregava-se o homem dos rebanhos e a mulher cuida da agricultura. Esta divisão social do trabalho, desenvolve a firme convicção que a fecundidade feminina exerce uma "grande e benéfica influência sobre a fertilidade das plantas". A leitura social revela que a divindade soberana passe a ser Terra-Mãe, a Grande Mãe, que tem como função a fertilização do solo e tornar fecundos os rebanhos e os homens.

Neumann (1955) quando analisa o arquétipo feminino refere-se, dentro dos aspectos de estudo da psicanálise, à imagem primordial ou arquétipo da Grande Mãe como a uma "imagem interna, trabalhada no interior da psique humana". A relação existente entre a construção e elaboração dessa psique, sofre influência de uma historicidade e, como tal, opera transformações, marca e define. Crê o mesmo autor, que a expressão simbólica deste fenômeno psíquico fundamenta-se nas figuras das Grandes Deusas, representadas nos mitos e criaçőes artísticas do genero.

O anonimato impessoal do arquétipo, termo utilizado pelo mesmo autor, fundamenta, a nosso ver, a ausência de preocupação e/ou intenção das civilizaçōes e do homem em individualizar o arquétipo feminino, especialmente quando remete-nos aos egipcios, os quais utilizavam o termo "a Grande" - referindo-se às deusas, ou então o plural utilizado por Goethe, no Segundo Fausto, Mães. Observamos, aqui, juntamente com Loraux (Duby et al., 1990), como o feminino singular torna-se genérico e o plural passa a ser coletivo. Acredita a autora que a idéia principal e que deve permanecer é a de que o feminino é por essência arquétipico, só podendo ser captado no modo impessoal ou mesmo no transpessoal.

Esta transpessoalidade, como o ser além do mundo e o significado de universalidade a que nos impulsiona é, de fato, aquilo em que se baseia a visão do arquétipo feminino. É mais do que uma aderência, é uma impregnação histórica, social e psicológica que nos permite estabelecer a identidade dessa mulher sem, no entanto, individualizá-la. A evidência que construiu-se por si só,correspondeu, primordialmente, ao destino biológico da mulher, divino, genérico, coletivo, mas jamais de "persi".

\section{O INÍCIO DO cUIDAR - gênero feminino}

Com base nas considerações anteriores, tornou-se interessante estabelecer um maior contato com o desenvolvimento histórico das práticas de saúde e que lugar coube a esta mulher- arquétipo.

As formações sociais tomam sempre as formas que o período histórico lhe permite e constrói de tal monta que as relaçōes de poder, as articulaçőes entre o Estado e a sociedade terminam por delinear a" evolução e trajetória das práticas de saúde" como defende Geovanni 
(1995) e observaremos em outros aspectos referidos por Dagmar citado por Waldow (1995).

Nos ateremos a situações pertinentes ao surgimento e inserção da mulher neste universo, referendando o que o SER ENFERMAGEM.

Parece-nos haver um senso comum que determina as propriedades e características das categorias profissionais, seguindo padrões da categoria gênero e que, como tal, atribui peculiaridades em seu exercício como que atributos de um ou outro genero, no caso o feminino. A observação do comportamento dos grupos nômades primitivos ainda que suscinto, permitenos entender que ao homem competia as "funções patriarcais, deixando para as mulheres a habilidade psicomotora da prática do cuidar" fundamentada pela sua inserção na divisão social do trabalho atrelada ao domínio privado (Georanini, 1995).

$\mathrm{O}$ atendimento às necessidades básicas de saúde, nesse grupo, tinha por objetivo assegurar a sobrevivência e estava, inexoravelmente, "associadas ao trabalho feminino". A assimilação do processo de cura como um resultado "do cuidar" e o significado dessa cura leva o homem a apoderar-se do "conhecimento dos meios de cura", estabelecendo assim o poder através do cuidar e curar. Posteriormente, no período das práticas de saúde denominado mágicosacerdotais, que ocorre por volta do Séc. V a.C., a única presença apontada do trabalho feminino refere-se à realização de partos domiciliares e a divisão "das atividades no templo com os sacerdotes", desenvolvidas por" mulheres de classe social elevada".

No alvorecer da ciência, que se inicia no Séc. $V$ a.C. e que vai até os primeiros séculos da Era Cristã, o surgimento da filosofia, a exaltação a princípios matemáticos e geométricos, proporcionam ao Homem novas atenções desvinculadas da crença nos Deuses. Nesse contexto em que é atribuido um considerável "status quo" ao pensar, a medicina grega desvincula a "arte do cuidar dos preceitos místicos e sacerdotais" mas, ainda assim, o cuidado dos doentes era executado por sacerdotes, feiticeiros e mulheres, correspondendo, também, ao perfil que começava a ser traçado pelos hindus como predicados daquele(a) que cuida: asseio, habilidade, inteligência, pureza e dedicação.

Seguramente é no período "monástico-medieval" do Séc. V ao XIII que ocorrem grandes modificações sociais, repercutindo na qualidade de vida dos povos, que assolados pelas "guerras bárbaras, associado à devastação da Europa ocidental e à queda do Império Romano", bem como epidemias de grande vulto (sífilis e lepra), é que se observa a busca do conforto espiritual na religião, sobressaindo-se, aí, o cristianismo como mentor, administrador e regulador do bem estar da alma e dos corpos.

O alastramento desse evento é, obviamente, desencadeado por esse mundo decadente, dilacerado por guerras e infestado por doenças, resultando no reflexo à busca da religiosidade. Acreditamos que, este momento, possa corresponder a uma fase histórica da Enfermagem na medida em que, como mulheres, submissas a uma ideologia dominante - a Igreja - integramos um fato social, junto ao papel do poder emergente, no sentido e "objetivo maior do bem estar espiritual e a salvação da alma do enfermo" (Dagmar citada por Waldow, 1995). Não éramos a Enfermagem, éramos os instrumentos, as mãos e os rostos da lgreja! Reproduzíamos os cuidados do domínio privado da mulher, tentando, quem sabe, pela primeira vez, ainda que sob os auspícios da Igreja, torná-lo público.

Com a construção dos primeiros hospitais pelas ordens e congregações religiosas fica definitivamente vinculada a prática de saúde aos mosteiros, o que determinará mais tarde, em razão da "forte motivação cristã", o direcionamento da mulheres em busca de exercitar "a caridade, proteção, e assistência aos enfermos". Assim, desse momento em diante, surge a prática da Enfermagem, como atividade desprovida de teor científico, e eminentemente leiga. Os treinamentos de Enfermagem eram executados pelas religiosas nos conventos e a formação a qual submetiam-se aquelas mulheres era de grande e forte apelo moral e disciplinar, compondo o que o senso comum da posteridade, entendeu ser, não uma profissão, mas sim um sacerdócio. Já em fins do século XIII e início do século XVI, pós-monástico, os regimes feudais 
encontram sua decadência com o surgimento e ascensão de mudanças revolucionárias na economia, que terminam por traçar, em seus desdobramentos, caminhos diferentes às práticas de saúde, libertando a prática médica dos claustros para as universidades, contrariamente à prática de Enfermagem, que permanece ligada à prática religiosa. Consideramos que, neste momento, face ao desprestígio social da mulher, fosse compreensivel o fato de que permanecesse, obscura, protegida - sob o arcabouço da religião - e longe do mundo intelectualizado do homem ao qual, certamente, não obteria lugar. Tal construção ideológica, mesmo que corresponda a certo periodo, dissimulou-se por muitos anos.

Abandonando a "era das luzes", procede-se ao que Dagmar (citada por Waldow, 1995)) denominou o momento "obscuro e decadente" da Enfermagem, como consequência das mudanças econômicas determinadas pelo Capitalismo emergente, o Renascimento e a Reforma Protestante. O perfil religioso daquelas que cuidam submerge, e o cuidado fica a critério de mulheres marginalizadas pela sociedade. No entanto, a obscuridade e decadência, apontada pela autora como caracteristíca histórica de um período da Enfermagem é na realidade a perversidade social que enquadrou e discriminou a mulher, tendo como base o exercicio de sua sexualidade, que contrapunha-se aos "valores morais" da epoca em questão.

O mundo modemo, entendido a partir da Revolução Industrial, vai do séc. XVI ao séc. XIX e dará lugar ao surgimento da Enfermagem Moderna, na Inglaterra, através de Florence Nightingale que, mantendo as caracteristicas preconizadas do arquétipo, elabora o perfil da candidata à Enfermeira: "TER ABNEGAÇÃO ABSOLUTA, ALTRUÍSMO, ESPÍRITO DE SACRIFÍCIO, INTEGRIDADE, HUMILDADE E, ACIMA DE TUDO, DISCIPLINA".

Como enunciamos, o papel atribuido à mulher nos "grupos nômades primitivos", termo combatido por Labra (1989) que o considera impróprio e afirma ser "uma abstração, pois não existe um modo de produção primitivo", (acreditamos que as sociedades foram assim denominadas por Georanini (1995), no intento de proporcionar uma contextualização temporal) transporta-se pelos periodos históricos, sofre a influência de diferentes formações sociais, em nações e comunidades diversas, determina condiçōes e modos sociais de opressão diferenciados, sendo incorporado por fim, como valor sócio-cultural, o que the permite adquirir o perfil da institucionalização do CUIDAR, como sinonimia do trabalho feminino.

A Enfermagem, através dessa mesma história internaliza o arqúetipo feminino, projetado pelo inconciente coletivo, não olvidando, no entanto à possibilidade de evolução desse arqúetipo através dos periodos históricos humanos. O modelo nightingaleano, ainda que aponte para a arkhè, vocacional e disciplinar, e que configure a criação da enfermagem moderna, traz consigo a imagem da divinização, "nossa sagrada labuta" como a ascenção ao divino, assemelhado ao arquétipo feminino. Assim, este modelo não deve ser entendido como o protótipo da construção da Enfermagem Modema enquanto profissão mas, sim, inversamente, como uma caracteristica do arquétipo feminino.

Podemos sugerir que a representação social da Enfermagem constroi-se sob o CUIDAR, o qual é motivado pela característica arquetípica feminina de PROTEÇÃO, PROMOÇÃO E PRESERVAÇÃO dos seres humanos. É a consequência de todo um intrincado e complexa visão da mulher, através da história, fato corroborado por NEUMANN, quando afirma que o efeito deste arquétipo, talvez prossiga totalmente, através da história...". Somos mulheres-deusas?

\section{O CUIDAR/CUIDADO - uma transpessoalidade feminina}

A medida em que evolui o conhecimento cientifico, observamos uma diminuição do grau de humanização do nosso mundo. O ser humano moderno possui dificuldades em integrar conceitos do inconsciente, instintivos, espirituais à sua consciência, pois privou-se dos meios.

Segundo Roach, citada por Waldow (1995), o mundo enfrenta, hoje, uma crise de desintegraçăo cultural, ética e ecológica, determinando, assim, o prejuizo da espiritualidade. 
Contudo, em meio a essa crise, surge um movimento de combate à violência e a desumanização - um novo paradigma, holistico.

O holismo, abrangendo a idéia de conjuntos, ou de todos, da totalidade, não engloba apenas a esfera física mas, também, as mais altas manifestações do espirito humano.

É importante registrar, que o ser humano moderno é, na verdade, uma curiosa mistura de características adquiridas ao longo da evolução mental milenária.

De acordo com essa "herança", faz parte da natureza humana o cuidar/cuidado humano - que constitui o modo humano de ser, ou seja, ele é essencial para o desenvolvimento e realização, enquanto seres humanos. "A capacidade de cuidar está enraizada na natureza humana; basicamente individuos cuidam porque são seres humanos." (Roach, citada por Waldow, 1995).

Nas diversas sociedades, a tecnologia encontra-se crescente e dinâmica e, paralelamente, observamos o oportuno resgate do cuidado humano. Cuidado humano este entendido como valores que priorizam a liberdade, o amor, o respeito, a saúde, a paz - estado de consciência e não, ausência de conflito.

Entendemos, como Waldow (1995) que, invarialvelmente, na familia, no trabalho, e em grande parte dos lugares, ocorrem relações de cuidado e que, portanto, é um modo de ser, uma atividade recíproca de ajuda que promove crescimento e auto-realização, além de uma dimensão ética e moral. Mas cuidar, também é uma forma de conhecer, ser e perceber. É o ser (modo de ser e agir), estar (presença) e fazer (atuar) cuidado.

Percebemos, então, que cuidar/cuidado não é apenas um privilégio ou caracteristica da Enfermagem. Contudo, observa-se que a mesma possui vários requisitos e atributos que a distinguem e a configuram como sendo uma profissão de ajuda, na qual o conceito de cuidado é genuíno como elemento abrangente de todas as disciplinas humanas e de ajuda.

São emergentes estudos e discussões considerando o cuidado humano, característica única e essencial da Enfermagem. Dentre as possiveis razões que movimentam as pessoas ao cuidar na Enfermagem, acredita-se que seja o forte apelo contingencial exercido pela presença da mulher na profissão, condicionado à aspectos culturais e arquetípicos, que prescrevem as atividades de cuidar como responsabilidade da mulher, internalizadas nos primórdios de sua vida.

Torna-se interessante sugerir que a Enfermagem possui toda uma estrutura alicerçada por arquétipos femininos, tanto por desenvolver atividades histórico-culturalmente consideradas do genero feminino, como por ser composta basicamente por mulheres. Tentaremos esboçar, resumidamente, alguns aspectos do CUIDAR/CUIDADO na Enfermagem - sua razão existencial.

Desde Florence Nightingale a palavra "care" tem sido utilizada na Enfermagem como verbo, como ser cuidado por, cuidar de outros ou para manifestar cuidado com interesse, compaixão por outro ser humano. Boemer (1984) define a palavra "care/caring", com o propósito heurístico (caminho para descobrir a verdade),genericamente, como aqueles atos de assistir(ajudar), suportar ou facilitar sobre ou para outro indivíduo ou grupo, com necessidades existentes ou previsiveis, para melhorar ou aperfeiçoar a condição humana ou modo de vida. "Caring" é ainda definido como aqueles comportamentos profissionais cognitivos, culturalmente aprendidos, técnicas, processos ou padrões que ajudam o indivíduo, familia ou comunidade a prover ou manter uma condição favorável de saúde ou modo de vida.

Do ponto de vista da Enfermagem, a idéia de "care" para si e para os outros é uma forma das mais antigas da expressão humana e, desde o início, "care" aparece como fator crítico em trazer crianças ao mundo, em estimular crescimento individual e "em ajudar" pessoas a sobreviver a uma variedade de experiências estressantes. Seu conceito tem sido utilizado, há tempos pela Enfermagem, mas os enfermeiros não têm realizado uma investigação mais cuidadosa dos aspectos linguísticos, culturais e do impacto social dos seus comportamentos e processos.

Ray, citado por Boemer (1984), propõe uma análise filosófica do "caring", ao discorrer 
sobre os vários fatores que afetam a situação atual da enfermagem dentro da cultura, enfatizando que o elemento essencial é "compreender o outro", "experimentar o outro lado". Esse termo é percebido como uma co-presença, dando, recebendo, comunicando e, sobretudo amando.

O "caring" refere-se àquelas relações que interligam sua estrutura aos vários processos ou partes do sistema que têm sua origem na aplicação da prática de enfermagem, como força de vida, situado-se como um componente essencial, talvez o mais essencial e, nesse conceito, ajuda os vulneravéis, educa a população e promove o interrelacionamento humano para satisfação de experiência de prazer, segurança, confiança, crescimento e atividades positivas. Desta forma, amor, ódio, medo, felicidade, perigo, prazer e outras emoções humanas podem ter uma produção de crescimento, geração de energia, motivação e outros efeitos positivos. É ainda um processo e uma forma de arte, com aspectos teóricos, filosóficos e práticos e, como tal, requer três elementos: compromisso, estudo continuo da teoria, filosofia e prática constante.

Segundo Watson citada por George (1993) quando se fala da Teoria Transpessoal de Cuidar/Cuidado, a Enfermagem consiste na ciência e na filosofia do cuidar/cuidado. Os princípios científicos para o cuidar/cuidado não possuem neutralidade em relações aos valores humanos não podendo manter-se indiferente às emoçöes humanas. Conseqüentemente, podemos considerar que as intervenções realizadas no cuidado humano necessitam de uma intenção, um desejo, um relacionamento e ações. Para a autora, o cuidado é visto numa perspectiva espiritual, existencial e fenomenológica - "a experiência humana é transcendental, significando Ser além do mundo".

No cuidado humano, na relação da enfermeira com a outra pessoa ocorrem trocas de suas histórias de vida e seus campos fenomenológicos, esforços transpessoais do ser humano para ser humano, no sentido de PROTEGER, PROMOVER e PRESERVAR a humanidade.

Ao pressuposto por Watson, temos à impressão de que estamos retroagindo no tempo e, pisando no solo da antiguidade, do divino e da Teoria dos Arquétipos, defendida por Jung, bem como a conotação do papel histórico-social atribuido à Terra-Mãe, a Grande Deusa, a Grande Mãe, ao arquétipo feminino/mulher.

Na premissa básica da Teoria Transpessoal do Cuidar/Cuidado, podemos observar forte congruência com a hipótese transcendental do arquétipo, excetuando a referência à atemporalidade, não adotada por Watson (George, 199.3) "A mente e as emoções de uma pessoa são janelas para a alma. O cuidado de Enfermagem pode ser, e é, físico, processual, objetivo e real, mas no mais alto nivel da Enfermagem, as respostas de cuidado humano das enfermeiras, as transações de cuidado humano e a presença das enfermeiras na relação transcendem o mundo físico e material, presas no tempo e no espaço e fazem contato com o mundo emocional e subjetivo da pessoa, como caminho para o self interior e para uma sensação mais elevada do self."

A proposição da atemporalidade junguiana, é de fato o arremesso do ser humano à universalidade, ao além do mundo, "fazendo contato com o mundo emocional e subjetivo da pessoa" (Watson citada por George, 1993), mas decerto, nunca mantendo-nos como propõe a autora - presas no tempo e no espaço -, pois isto negaria a característica humana do dinamismo e da busca da arkhé, que certamente não era exclusividade dos primeiros filósofos.

\section{CONSIDERAÇÕES FINAIS}

O estudo bibliográfico e reflexivo a que nos propusemos, abordando a Teoria do Arquétipo, buscando uma leve intimidade com o Inconsciente Coletivo e, que transpassasse a Enfermagem, da sua origem e prática, centrada no CUIDAR, não nos permite escapar, sem mergulhar no terreno arenoso da transpessoalidade.

Sentimo-nos englobadas e abraçadas por essa universalidade, que permite o contato com a subjetividade do ser humano. Obviamente, a atividade do CUIDAR, segundo essa 
perspectiva, torna-se imensúravel, de natureza suprapessoal e deve ser vista como uma experiência humana transcendental, deserdada dos conceitos mecanicistas, tayloristas e positivistas por excelência. Ser além do mundo, pressupõe o teor existencial da raça humana, permite o fenômeno, convive com a possibilidade do espiritual.

O quebra cabeças em que configurou-se a história da Enfermagem, recortado por visões ideológicas, utópicas, versões e indagações, trata o sujeito-agente do cuidar, como alvo dos fatos e movimentos históricos-sociais. No entanto a presença da mulher nessa historicidade, a totalidade e contradições, permite-nos mesmo pressupor que a Teoria do Matriarcado, defendida por Bachofen (Duby et al., 1990) possa, de fato, ter ocorrido na antigüidade.

No entanto, à luz de nossa pouca vivência profissional, observamos que essa atividade essência do SER ENFERMAGEM embute, em suas bases, e por que não dizer, reveste-se de uma celestialidade quando exalta o compromisso de PROTEGER, PROMOVER e PRESERVAR o ser humano, caracteristicas que transcendem o mundo físico e material, remetendo-nos a figura arquética da Grande Mãe.

Nossa vivência, enquanto enfermeiras obstétricas, em instituições de caráter docente e assistencial, permitiu-nos, através do convivio e observação assistemática, considerar que as formas arquetipicas do feminino são invariáveis, no entanto, o conteúdo é passível de transformações. O próprio Clarke (1992), afirma "que não significa que estamos presos numa camisa de força arquetipica e, por isso, impedidos de buscar e trabalhar pela mudança social".

Não duvidamos que a Enfermagem possua, talvez, até por um contigente populacional expressivamente feminino, influências e principios da Teoria dos Arquétipos.

Cremos que, ainda assim, não devemos omitir-nos de outro viéis, que pode supor serem os arquétipos a materialização da forma de uma ideologia bursguesa ocidental, disfarçada como Clarke (1992) mesmo denomina "de valores ocidentais modernos".

A emergência da Teoria dos Arquétipos, bem como do Inconsciente Coletivo, coincide com o surgimento do Materialismo e do Positivismo de Conte sobre o qual construiu-se o modelo filosófico da Enfermagem, que negou a subjetividade e transpessoalidade do ser.

A partir de todas as reflexões elaboradas, acreditamos que o profissional de Enfermagem possua, sim, aquele inconsciente individual, construido por experiências e aquisições pessoais; mas inegavelmente estratifica-se sobre uma camada mais profunda. Não é "uma tábula rasa," sofre influências no mais alto grau de predisposiçōes herdadas do inconsciente coletivo, latente em elementos arcaicos, lançando-nos à universalidade, à transpessoalidade e à atemporalidade.

Sugerimos, em função dessas consideraçōes, que a representação social da Enfermagem construiu-se, sob um CUIDAR alicerçado no Arquétipo Feminino de PROTEÇÃO, PROMOÇÃO E PRESERVAÇÃO dos Seres Humano.

Arquetipicamente, somos Deusas?

\begin{abstract}
The present study proposes a new approach to the feminine origins of nursing, utilizing an archetypical framework, analysing the features of this profession which has changed very little along its history. The article advocates that nursing characteristics are the result of a collective unconscious, that is, a primitive model of innate ideas. The perspective adopted for a feminine archetype in this investigation are related to the historical and social basis of nursing, as well as, with its pre-defined objective which is caring. Utilizing their own professional experience throughout the years, the authors identity that the essence of the nursing profession is caring and that this act, which involves protecting, promoting and preserving the human being, is basically associated to women. Based on these reflections, the authors advocate the idea nurses have an individual conscience that is influenced by a collective unconscious which is inherited.
\end{abstract}

KEYWORDS: feminine archetype, nursing, care 
RESUMEN: El presente trabajo propone un nuevo enfoque sobre el origen femenino de la Enfermería a partir de la óptica arquetípica y de sus caracteristicas tan poco mutables en el trascurso de la historia. Creemos que las mismas sean resultantes de un inconsciente colectivo, o sea, un modelo primitivo, ideas innatas. Las perspectivas adoptadas del arquético femenino serán relacionadas, con la base histórica y social de la Enfermeria y con la presupuesta actividad-fin de cuidar, donde estarian sus (in)visibles influencias en Enfermeria. Durante años y a la luz de nuestra vivencia profesional, hemos identificado que la actividad-esencia de la profesión - EL CUIDAR-tiene el sentido básico del género femenino -PROTEGER, PROMOVER, PRESERVAR al ser humano, características estas que trascienden el mundo físico y material. A través de esas reflexiones sugerimos la posibilidad de que las (los) enfermeras (os)posean una consciencia individual, que no corresponde a una tabla rasa, mas que sufre influencia de predisposiciones heredadas que han constituido el inconsciente colectivo.

PALABRAS CLAVE: arquetipo femenino, Enfermería, cuidar

\section{REFERÊNCIAS BIBLIOGRÁFICAS}

BRANDÃO, Juanito S. B. Mitologia Grega. 4.ed. Petropólis: Vozes, 1988. v. 1.

CHAUI, Marilena. Convite à Filosofia. 2.ed. Rio de Janeiro: Ática, 1994.

Introdução à História da Filosofia. Rio de Janeiro: Ática, 1995.

CLARKE, J. J. Em Busca de Jung - Indagaçōes Históricas e Filosóficas. Rio de Janeiro: Ediouro, 1992.

DUBY, G. et al. História das Mulheres - A Antiguidade. Porto: Afrontamento, 1990. v.1.

GEORGE, Júlia B. et al. Teorias de Enfermagem -Fundamentos para a Prática Profissional. Porto Alegre: Artes Médicas, 1993.

GEOVANINI, Telma et al. História da Enfermagem - versões e indagaçōes. Rio de Janeiro: Revinter, 1995.

JUNG, Carl G. Arquetipos $\theta$ Inconsciente Colectivo. Buenos Aires:Editorial Paidos, 1970.

O Homem e seus Simbolos. Rio de Janeiro: Nova Fronteira, 1964.

LABRA, Maria E. Mulher, Saúde e Sociedade no Brasil. Petropólis Vozes, 1989.

NEUMANN, Erich. The Great Mother - An analysis of the arquetype feminine. Londres: Routledge and Kegan, 1955

WALDOW, Vera R. et al. Maneira de Cuidar - Maneira de Ensinar - A Enfermagem entre a escola e a prática profissional. Porto Alegre: Artes Médicas, 1995. 